\title{
Measurements of Mean Initial Velocities of Analyte and Matrix Ions in Infrared Matrix-Assisted Laser Desorption Ionization Mass Spectrometry
}

\author{
Stefan Berkenkamp, Christoph Menzel, Franz Hillenkamp, \\ and Klaus Dreisewerd \\ Institute of Medical Physics and Biophysics, University of Münster, Münster, Germany
}

\begin{abstract}
The mean initial velocities of analyte ions ranging in molecular weight from $1000 \mathrm{Da}$ to 150 $\mathrm{kDa}$ and desorbed with a pulsed Er:YAG laser from various solid-state and liquid IR MALDI matrices were measured along with those of the matrix ions. Experiments with UV MALDI were performed for comparison in addition for a 2,5-dihydroxybenzoic acid preparation. Two different measurement principles were employed, (1) a delayed extraction method, relying on the initial velocity-dependent increase of flight times with delay time between laser and HV ion extraction pulse, and (2) a field-free drift method in which the first region of a two-stage ion source was varied in length and the flight times compared. The two methods yielded somewhat different values for the mean initial ion velocities. Based on a detailed discussion of the measurement principles it is suggested that the actual initial velocities of IR MALDI ions lie between the limits set by the two methods. The influences of the analyte-to-matrix ratio, laser fluence, and laser wavelength on the initial ion velocities were also investigated. Significant differences between the desorption mechanisms for liquid and solid-state matrices were observed. (J Am Soc Mass Spectrom 2002, 13, 209-220) () 2002 American Society for Mass Spectrometry
\end{abstract}

$\mathrm{M}$ easurements of the initial kinetic energy of ions and particles form a straightforward approach for investigations on the mechanistics of laser desorption and laser desorption/ionization processes. In time-of-flight (TOF) mass spectrometry, the large and mass-dependent initial kinetic energies of analyte ions in matrix-assisted laser desorption ionization (MALDI), along with a large width in the energy distributions have moreover posed substantial limitations on the instrumental performance for a long time. With state-of-the-art delayed extraction (DE) $[1,2]$ instruments these problems can now partly be overcome $[3,4]$, although sophisticated calibration procedures incorporating explicit initial velocity values are required $[5,6]$. The determination of the initial velocities of MALDI ions has, therefore, found substantial interest in the last years also from this practical viewpoint.

A relatively large number of studies on the kinetic energies of laser desorbed ${ }^{*}$ particles or ions have been performed in the past. With respect to mass spectrometry these studies focused on either direct laser de-

Published online January 16, 2002

Address reprint requests to Dr. K. Dreisewerd, Institute of Medical Physics and Biophysics, University of Münster, Robert-Koch-Str. 31, D-48149 Münster, Germany. E-mail: dreisew@uni-muenster.de sorption/ionization (LDI) with pulsed infrared (IR) and ultraviolet (UV) lasers, e.g., [7-15] or, more relevant for this work, MALDI-MS [5, 16-28] with pulsed ultraviolet lasers. The first measurements of initial ion velocities in infrared MALDI were reported only very recently by Ermer et al. [29].

Different experimental approaches for the determination of initial (ion) velocities have been pursued in these studies. A survey of the employed techniques for UV MALDI has recently been given by Glückmann and Karas [17]. Following their classification, the techniques can essentially be arranged into three groups.

In the so-called delayed extraction methods (DEM) $[5,16,17]$, the mean initial axial velocity is deduced from the change in overall ion flight times upon variation of the delay time applied between laser and ion extraction pulse in the ion source. In the field-free drift methods (FFDM) initial velocities have been deduced either purely from the drift time in a field-free region

\footnotetext{
*We will use the common mass spectrometric notation "laser desorption" (as in MALDI) equivalent to "laser ablation" throughout this article although both form by definition clearly different processes-laser-induced surface desorption/evaporation of single molecules and ions versus ablation of bulk material. In fact, for the typical fluence range, MALDI will resemble a volume rather than a surface process, in particular for the IR-MALDI case.
} 
[29], a comparison between the flight times with and without a field in a first ion stage region [18, 19], or in orthogonal acceleration geometries in which ions were extracted perpendicular to their centre of mass movement, after passing through a field-free region $[15,20]$. In yet another variant initial ion velocities were determined in a modified Wiley-McLaren set-up [23].

A considerably different approach is the determination of initial velocities by the postionization of desorbed neutral molecules. Here, usually the delay time between desorption and postionization laser pulses is varied and velocities are determined from the ion intensity versus delay time distribution $[8,21]$. Finally, a laser induced fluorescence (LIF) technique has been employed to characterize UV MALDI plume dynamics [27]. The experimental studies have been supplemented by a number of theoretical studies [30-32] and more recently, by molecular dynamics simulations (MD) [3337].

It should be emphasized that for principle reasons none of the methods including the experiments introduced in this paper is capable of really reflecting the temporal evolution of the condensed phase disintegration and early plume expansion. Instead, essentially all techniques rely on the measurement of flight times after the plume has expanded over a considerable distance. Moreover, all measurements are based on the detection of ions which form only a small fraction of the dense neutral particle cloud. The term initial, therefore, appears rather undefined. Collisional interactions during the early phase of plume expansion can be expected to lead to substantial changes in the three-dimensional initial velocity distributions. Works by Noorbatcha et al. [38] and Kelly et al. [39] have, for example, demonstrated that even in the case of the removal of very low amounts of material on the order of a monolayer and below, a Knudsen-layer will generally be fully developed, involving a sufficient number of collisions to dynamically change the distributions and eventually determine the overall gas-phase dynamics.

In this work initial velocity will be understood in the usual way as the free expansion velocity into the vacuum of the TOF spectrometer ions have acquired after essentially all interactions in the expanding plume are complete. Moreover, one has to differentiate between mean overall velocity and mean axial velocity, the latter is essentially determined. This is a convolution of mean velocities of ions and the angle-dependent transmission of the instrument.

Considerably different values for the mean initial velocities of UV MALDI ions have been reported in the previous studies. Mean initial velocities between about 200 and $650 \mathrm{~ms}^{-1}$ have, for example, been reported in a study by Glückmann et al. employing the DE method [17]. In other publications considerably higher initial velocities closer to $1000 \mathrm{~ms}^{-1}$ were reported for comparable analyte matrix systems [18, 20, 23, 29]. Surprisingly, these obvious differences have hitherto hardly been addressed in pertinent literature. Comparing the

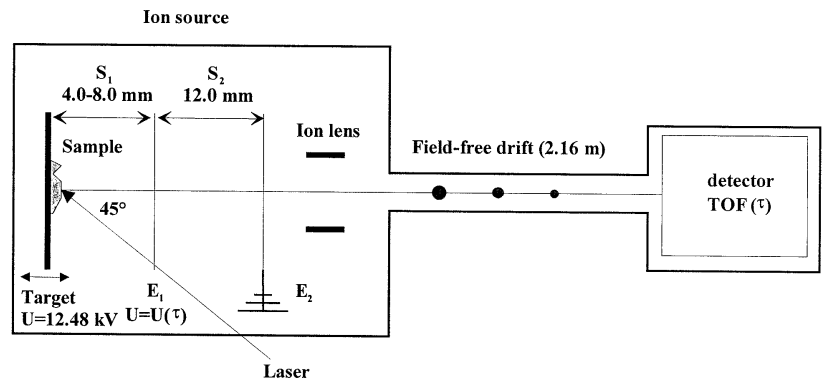

Figure 1. Schematic diagram of the ion source of the mass spectrometer. See Table 1 for values of distances and applied voltages.

DEM and the FFDM experiments, generally higher values were determined if the FFD method was used, suggesting that the major reason for the observed differences may be related to the measurement method.

In other studies, mean axial ion velocities, i.e., the velocity component in the direction of the sample normal, were found to be significantly higher than the corresponding radial components [19, 23]. Consequently, MALDI-plumes are strongly forward-peaked. The diverse outcome of the different experiments can therefore possibly be attributed to the discrimination of off-axial plume components, in particular by the FFD method.

The present article addresses the mean initial velocities of IR MALDI generated analyte and matrix ions, investigated with respect to the most relevant sampleand laser-related parameters, the type of matrix, molecular weight of the analyte and the molar analyte-tomatrix ratio, as well as the laser fluence and wavelength. Special attention is paid to a comparison between solid-state and liquid matrices. Peptides and proteins were investigated as analyte molecules.

In order to evaluate and control possible instrumental influences and artifacts due to the measurement principle to some extent, the two most important, independent methods were employed and compared: (1) A delayed extraction method (DEM) and (2) a field-free drift method (FFDM) in which the length of the field-free expansion region was varied.

\section{Experimental}

\section{Mass Spectrometer}

All experiments reported here were carried out with an in-house built time-of-flight mass spectrometer in the positive ion and linear TOF mode, with a field-free drift length of $2.16 \mathrm{~m}$. The residual pressure in the mass spectrometer was typically $(1-3) \times 10^{-6} \mathrm{mbar}$. Ions are accelerated in a split extraction source (Figure 1). The target is mounted on a precision linear motion drive. The distance $S_{1}$ between target and first extraction mesh electrode can be varied between 2 and $8 \mathrm{~mm}$. Electrodes $E_{1}$ and $E_{2}$ are electro-formed nickel meshes of $\sim 90 \%$ optical transmission (70 lpi, MN-17, Buckbee Mears St. 
Paul, St. Paul, MN). A venetian-blind secondary electron multiplier (9643/A, Emi-Thorn, Ruislip, UK), equipped with a conversion dynode, mounted $10 \mathrm{~mm}$ in front of the first dynode, is used for ion detection. After preamplification, signals are digitized by a transient recorder (LeCroy 9354, Chestnut Ridge, NY) and transferred to a PC. Signal processing is done with an in-house developed program for data acquisition and evaluation (ULISSES, Chips Work, Bonn, Germany). A CCD camera is used for sample observation and laser spot localization with a resolution of $\sim 20 \mu \mathrm{m}$.

Three different IR lasers were employed. A Q-switched Er:YAG laser (Speser, Spectrum $\mathrm{GmbH}$, Berlin, Germany) emitting at $2.94 \mu \mathrm{m}$ served as the standard IR desorption/ionization laser. The shot-toshot pulse energy stability of this laser is $\pm 5 \%$. For the experiments on possible wavelength effects, a Q-switched Er:YSGG laser (SEO 1-2-3, Schwartz Electro Optics, Orlando, FL) emitting at $2.79 \mu \mathrm{m}$ and a TEA$\mathrm{CO}_{2}$ laser (Laser Science, Inc., Franklin, MA) emitting at $10.59 \mu \mathrm{m}$ were additionally employed. The pulse width of all lasers was adjusted to 80-90. All IR lasers were coupled into the mass spectrometer via the same vacuum port. Care was taken by appropriate choice of the focusing optics so that the focal laser spots on the target were in the range of 100 and $200 \mu \mathrm{m}$ in diameter and comparable for all lasers. The angle of incidence was $45^{\circ}$. In case of the Er:YAG and the Er:YSGG laser fluences could be adjusted continuously by means of a stepper-motor driven dielectric attenuator (Laser Optik $\mathrm{GmbH}$, Garbsen, Germany). Stacks of meshes of different transmission served as attenuators for the $\mathrm{CO}_{2}$ laser. Laser pulse energies were measured by placing the head of a high-precision energy meter (RK 3230. Laser Precision, Corp., Yorkville, NY) into the laser beam line behind the attenuators.

In the experiments to investigate the fluence dependence of the initial velocities a fiber optic based delivery system was used as described previously [42], in order to produce a desorption spot on the sample with a reasonably uniform fluence distribution, independent of the laser pulse energy. In short, the Er:YAG laser beam was coupled into a ca $1.8 \mathrm{~m}$ long sapphire fiber with a core diameter of $350 \mu \mathrm{m}$ (no cladding; Saphikon., Milford, $\mathrm{NH}$ ) and the intensity profile on the end face of the fiber imaged 1:1 onto the sample by two planoconvex lenses of $100 \mathrm{~mm}$ focal length.

For comparison, UV MALDI experiments were conducted with an $\mathrm{N}_{2}$ laser (VSL-337ND, Laser Science, Inc., Franklin, MA) emitting at $337 \mathrm{~nm}$ (pulse width, 3 $\mathrm{ns})$. This laser is coupled into the mass spectrometer via a separate port. The UV focal spot size is about $100 \mu \mathrm{m}$ in diameter and the angle of incidence $45^{\circ}$ as for the IR.

\section{Sample Preparation}

Compounds were purchased from commercial suppliers and used without further purification. Liquid matrices, glycerol, di-glycerol, triethanolamine (TEA), di- ethanolamine, and lactic acid were mixed with aqueous analyte solution on the stainless steel target. Typically, volumes of $0.5-1 \mu \mathrm{l}$ of aqueous analyte solution were mixed with $1-5 \mu \mathrm{l}$ of matrix to yield a molar analyteto-matrix $(\mathrm{A} / \mathrm{M})$ ratio of $10^{-6}-10^{-4}$. Prior to insertion into the high vacuum of the mass spectrometer most of the solvent water was gassed off for some minutes in the pre-vacuum (ca $10^{-2} \mathrm{mbar}$ ) of the sample transfer chamber. Because of the low vapor pressure of all matrices, $\mathrm{A} / \mathrm{M}$ ratios and sample morphologies, especially the thickness of the sample drop, did not change significantly during the time of the individual measurements.

Solid matrices, succinic acid, thiourea, and TRIS, were prepared using a thin-layer, fast evaporation technique for an optimal sample homogeneity: Volumes of $2-5 \mu \mathrm{l}$ of a ca. $10^{-1} \mathrm{M}$ aqueous solution of matrix were mixed with $0.5-1 \mu \mathrm{l}$ volumes of $10^{-6}-10^{-4}$ $\mathrm{M}$ aqueous analyte solution to yield $\mathrm{A} / \mathrm{M}$ ratios of $10^{-6}-10^{-3}$. The solvent was evaporated rapidly in the pre-vacuum to yield comparatively micro-crystalline, morphologically homogeneous samples with crystals of a few micrometers in size. To increase the sample thickness for a greater number of possible shots on the same spot, two to three analyte/matrix layers were usually prepared on top of each other. DHBs (in a mixture of $90 \%$ 2,5-dihydroxybenzoic acid and 10\% 2-methoxy-5-hydroxybenzoic acid), used for comparison between IR- and UV MALDI, was prepared by the dried droplet method: a volume of ca. $1 \mu \mathrm{l}$ of aqueous matrix solution was mixed on-target with $10^{-6}-10^{-4} \mathrm{M}$ aqueous analyte solution to yield molar $\mathrm{A} / \mathrm{M}$ ratios of $10^{-5}-10^{-4}$. In this case solvent evaporation was forced by a stream of cold air.

Ice matrix preparations, herein referred to as frozen hydrated preparations, were made by drying $10^{-3} \mathrm{M}$ aqueous analyte solutions onto the metal target under ambient conditions, as described previously [40]. Subsequently, these samples were cooled down by immersing the targets into liquid nitrogen before rapid transfer into the mass spectrometer. By this procedure a small amount of water of hydration was retained in the preparation. The relatively large heat capacity of the sample stage kept the sample below $-20{ }^{\circ} \mathrm{C}$ during the measurement.

\section{Determination of Mean Initial Ion Velocities}

\section{Delayed extraction method (DEM)}

In this approach data analysis relies on the change in flight time of the ions upon variation of the delay time between laser and ion extraction pulse.

Of utmost importance for the DE method is an as accurate as possible knowledge of the electric field in the first extraction region during the delay time before ion extraction. In this period it should be constant, in particular near the sample surface, and most conve- 
niently, zero. The electric field during ion extraction thereafter should also be very precisely defined .

Any deviation from the assumed field strength, caused, for example, by field penetration through the $\mathrm{E}_{1}$ mesh and/or drifts in the outputs of the power supplies for target and first extraction electrode strongly affects the flight-time curves and the derived velocities. These effects were, therefore, examined especially carefully. 3D-SIMION 6.0 simulations were performed to estimate the required reverse potential applied between target and $E_{1}$ to effectively compensate fringing fields. In these simulations a reverse voltage of $-20 \mathrm{~V}$ (for a total target potential of $12.5 \mathrm{kV}$ ) was found to reduce the residual field strength to below $0.3 \mathrm{~V} / \mathrm{mm}$ for a distance above the target from $\mathrm{z}=0 \mathrm{~mm}$ (target surface) to $\mathrm{z}=6.7 \mathrm{~mm}$ for an overall distance $S_{1}$ from target to first mesh of 8 $\mathrm{mm}$.

Experimentally, the field-free condition was verified by determining the flight time of low mass ions. $\mathrm{Na}^{+}$ ions were desorbed from the very thin inner area of a DHB dried droplet preparation, and their flight times measured as a function of delay time for ion extraction. For field-free conditions an increase close to linear in the flight time with delay is predicted by the flight time equations (eq 1). For poorly compensated fringing fields with a residual (accelerating) field strength of only a few volts $/ \mathrm{mm}$ in $\mathrm{S}_{1}$, the resulting curve is significantly parabolic (data not shown). By fine-tuning of two properly adjusted power supplies (SN series, FUG, Rosenheim, Germany) the time-of-flight curve of the $\mathrm{Na}^{+}$ions changes from a parabolic to an almost linear slope for optimal zero field approximation. In the overcompensated case with a decelerating field, the measured curves unexpectedly deviated from the predictions. Surprisingly, the experimental curves remained linear for increasingly large reverse fields up to $200 \mathrm{~V} / \mathrm{mm}$. The increase in flight-time is then exactly the delay time applied. This can be explained by the assumption that $\mathrm{Na}^{+}$ions remain mobile near or at the target surface and get accelerated by the full acceleration potential after the extraction field is switched on. A linear slope alone is, therefore, NOT a suitable criterion for zero field conditions. Instead, the rather sharp transition from non-linear to linear has to be carefully monitored. In agreement with the simulations throughout all experiments, zero-field conditions were realized by setting the target voltage to $12.480 \mathrm{kV}( \pm 2.5 \mathrm{~V})$ and $\mathrm{U}_{\mathrm{E} 1}$ to $12.500 \mathrm{kV}( \pm 2.5 \mathrm{~V})$. The accuracy of $\pm 2.5 \mathrm{~V}$ reflects the long-term thermal stability of the HV power supplies, determined in a separate experiment.

DE difference voltages $\mathrm{U}_{\mathrm{DE}}$ between 2.0 and $6.5 \mathrm{kV}$ were applied in the experiments. A systematic influence of the applied delayed extraction voltage on the initial velocity values determined by DEM was not observed for any of the matrices. Delayed extraction was realized with a home-built DE unit on the basis of a Behlke high voltage switch (HTS 80, Behlke Electronic, Kronberg, Germany). The DE HV pulse was applied to $\mathrm{E}_{1}$ and had a rise time of about $10 \mathrm{~ns}$ with minimal ringing. The target potential was blocked with a HV-capacitor in order to prevent a pull-down of the target voltage when pulsing the $\mathrm{HV}$ on $\mathrm{E}_{1}$. The delay time between laser and DE pulse can be varied from $100 \mathrm{~ns}$ to $10 \mu \mathrm{s}$.

Generally, one has to differentiate between a possible systematic error in the determination of the initial velocities, e.g., due to experimental uncertainties, and an uncertainty due to statistical variation of data (relative error). Both types of error are assessed separately below.

Major systematic errors in the determination of $\mathrm{v}_{0}$ result from the uncertainty in measurement of the length $S_{1}$ of the first extraction region (about $\pm 0.15 \mathrm{~mm}$ in this study), the ion acceleration region $S_{2}( \pm 0.1 \mathrm{~mm})$, the length of the drift path $( \pm 0.01 \mathrm{~m})$ and the applied voltages $( \pm 2.5 \mathrm{~V}$ per power supply), as well as the thickness of the sample. The latter shifts the desorption spot in the z-direction and introduces an additional dielectric. The transmission of the mass spectrometer was also found to influence the flight time distributions to some extent, e.g., if the desorption laser spot was located off ion-axis, which was, therefore, carefully controlled throughout the experiments.

Another minor source of error is that ion flight times were determined from the signal peak centroid. Any spread in initial energies combined with the variation of the delay time pulse must result in a delay time and energy spread-dependent transformation of the ion arrival time distributions at the detector. As a result, the peak shape is a convolution of a delay time-dependent function and the initial velocity or energy distribution; the latter is not known and cannot be derived from this sort of measurement. The mathematical treatment of this effect would need a proper knowledge of the energy spread in (IR) MALDI. It was, therefore, not accounted for in this study, nor has it apparently been addressed before.

Finally, the deceleration/acceleration in the Einzel lens used to focus the ions onto the detector and the post-acceleration in front of the detector introduce a (very) slight dispersion in the flight-time because of the delay time dependent kinetic energies of the ions leading to different acceleration times.

The different sources of error were found to influence the measurements differently for light and heavy ions. As a worst-case estimate for the given experimental set-up, the compounded maximum error of the above contributions, $\delta_{\mathrm{v} 0 \text {, max }}$ is estimated to $\pm 10 \%$ for all analyte ions. For the low-mass matrix ions the possible error is considerably larger and difficult to estimate since already very weak residual fields can lead to significant changes in the flight-time curves. The values given for matrix ions in Table 2 should, therefore, be taken with caution.

A critical evaluation of eq 1 and estimate of errors also revealed that the reliability of the DE method for the determination of the initial velocity $\mathrm{v}_{0}$ is considerably improved if a large $S_{1}$ is used in combination with long delay times $\tau$ and a low $\mathrm{U}_{\mathrm{DE}}$, and, further, if ions with high molecular mass are investigated. These pre- 
Table 1. Physical constants and parameters used in the experiments, in eq (1a)-(1d), and for the Levenberg-Marquard algorithm

\begin{tabular}{lll}
\hline$\tau$ & Run-time variable for Levenberg-Marquard fit & Delay time for ion extraction \\
$\mathrm{V}_{0}$ & Fit parameter for Levenberg-Marquard fit & Mean initial axial ion velocity \\
$\mathrm{C}$ & Scaling factor for Levenberg-Marquard fit & \\
$\mathrm{m}$ & $100 \mathrm{Da}-150 \mathrm{kDa}$ & Molecular weight \\
$\mathrm{S}_{1}$ & $8 \mathrm{~mm}( \pm 0.15 \mathrm{~mm}), 6 \mathrm{~mm}( \pm 0.15 \mathrm{~mm})$ & Length of 1. extraction region \\
$\mathrm{S}_{2}$ & $12.5 \mathrm{~mm}( \pm 0.1 \mathrm{~mm})$ & Length of 2. extraction region \\
$\mathrm{L}$ & $2.16 \mathrm{~m}( \pm 0.01 \mathrm{~m})$ & Overall flight length (without extraction stages and detector) \\
$\mathrm{U}_{\text {targ }}$ & $12480 \mathrm{~V}( \pm 2.5 \mathrm{~V})$ & Target voltage \\
$\mathrm{U}_{\mathrm{DE}}$ & $2 \mathrm{kV} ; 2.85 \mathrm{kV} ; 5 \mathrm{kV}$, or $6.5 \mathrm{kV}( \pm 10 \mathrm{~V}$ each) & Delayed extraction voltage (voltage difference between target \\
& & and first extraction electrode after HV-pulsing) \\
\hline
\end{tabular}

cautions have not been implemented in most of the previous studies $[5,17,41]$.

Each flight time was derived from a sum spectrum, comprising ca. twenty single shot exposures. In case of the solid-state matrices the target was moved to expose a fresh spot after two to three consecutive laser pulses. For the liquid matrices the laser spot did not have to be moved because of sample regeneration. The statistical variation in flight times, $\sigma_{\mathrm{T}}$, of the sum was determined for succinic acid and glycerol, representative for the liquid and solid matrix classes. For succinic acid $\sigma_{\mathrm{T}}$ was determined to be about $0.12 \%, 0.34 \%$, and $0.96 \%$ for delay times $\tau$ of $0-1.5 \mu \mathrm{s}, 1.5-4.0 \mu \mathrm{s}$, and $4.0-6.0 \mu \mathrm{s}$, respectively. The corresponding values for glycerol were $\sigma_{\mathrm{T}}=0.06 \%, 0.16 \%$, and $0.60 \%$. The increase of the $\sigma_{\mathrm{T}}$ values results from signal peak broadening with increasing $\tau$. The $\sigma_{\mathrm{T}}$ values were included in the Levenberg-Marquard algorithm from which the resulting standard deviation $\sigma_{\mathrm{v} 0}$ for the initial velocities $\mathrm{v}_{0}$ were derived. For all measurements $\sigma_{\mathrm{v} 0}$ was in the range of $1-3 \%$. This value is small compared to the accuracy of the method determined by the possible systematic error $\delta_{\mathrm{v} 0 \text {, max }}$ of $\pm 10 \%$.

\section{Data Analysis for DEM}

$\mathrm{v}_{0}$ was derived from a Levenberg-Marquard fit of eq $1 \mathrm{a}$ to the experimental data. Run time variable was $\tau$. The theoretical flight time of an ion of mass $m$ and charge number $Z=1$ is given by

$$
\mathrm{T}(\tau)=\tau+\mathrm{C}\left(\mathrm{T}_{\mathrm{S} 1}+\mathrm{T}_{\mathrm{S} 2}+\mathrm{T}_{\mathrm{TOF}}\right)
$$

with

$$
\begin{aligned}
\mathrm{T}_{S 1}= & \sqrt{\frac{2 \mathrm{~m}}{\mathrm{qU} \mathrm{DE}_{\mathrm{DE}}\left(1-\frac{\mathrm{v}_{0} \tau}{\mathrm{S}_{1}}\right)}} \cdot\left(\mathrm{S}_{1}-\mathrm{v}_{0} \tau\right) \\
& \cdot\left(\sqrt{\mathrm{k}_{1}}-\sqrt{\mathrm{k}_{1}-1}\right) \\
\mathrm{T}_{\mathrm{S} 2}= & \sqrt{\frac{2 \mathrm{~m}}{\mathrm{q}\left(\mathrm{U}_{\mathrm{targ}}-\mathrm{U}_{\mathrm{DE}}\right)}} \cdot \mathrm{S}_{2} \cdot\left(\sqrt{\frac{\mathrm{k}_{1} \mathrm{U}_{\mathrm{DE}}\left(1-\frac{\mathrm{v}_{0} \tau}{\mathrm{S}_{1}}\right)}{\mathrm{U}_{\mathrm{targ}}-\mathrm{U}_{\mathrm{DE}}}+1}\right.
\end{aligned}
$$

$$
\begin{aligned}
& -\sqrt{\left.\frac{\mathrm{k}_{1} \mathrm{U}_{\mathrm{DE}}\left(1-\frac{\mathrm{v}_{0} \tau}{\mathrm{S}_{1}}\right)}{\mathrm{U}_{\mathrm{targ}}-\mathrm{U}_{\mathrm{DE}}}\right)} \\
& \mathrm{T}_{\mathrm{TOF}}=\sqrt{\frac{\mathrm{m}}{2 \mathrm{q}\left(\mathrm{U}_{\operatorname{targ}}-\mathrm{U}_{\mathrm{DE}} \frac{\mathrm{v}_{0} \tau}{\mathrm{S}_{1}}\right)}} \cdot \mathrm{L} \cdot \frac{1}{\sqrt{\mathrm{k}_{2}}}
\end{aligned}
$$

where

$$
\mathrm{k}_{1}=1+\frac{\mathrm{mv}_{0}^{2}}{2 \mathrm{qU}_{\mathrm{DE}}\left(1-\frac{\mathrm{v}_{0} \tau}{\mathrm{S}_{1}}\right)}
$$

and

$$
\mathrm{k}_{2}=1+\frac{\mathrm{mv}_{0}^{2}}{2 \mathrm{q}\left(\mathrm{U}_{\mathrm{targ}}-\mathrm{U}_{\mathrm{DE}}\left(1+\frac{\mathrm{v}_{0} \tau}{\mathrm{S}_{1}}\right)\right)}
$$

$\mathrm{T}$ is the total ion flight time, $\mathrm{T}_{\mathrm{S} 1}$ and $\mathrm{T}_{\mathrm{S} 2}$ are the flight times in the first and second extraction region, $\mathrm{T}_{\mathrm{TOF}}$ is the flight-time in the rest of the mass spectrometer, $\tau$ is the delay time between laser and HV extraction pulse $\mathrm{U}_{\mathrm{DE}}$, and $\mathrm{q}$ the elementary charge. The definition of all other parameters and constants in the time-of-flight equations is given in Table 1 along with their experimental values where appropriate.

The factor $C$ in eq 1 a serves as scaling factor and is introduced into eq 1 to account for the observation of systematically longer flight times than predicted by the simple flight-time equation. In fact, $C$ compensates for effects of different origin. The first is a pool of not deconvolutable process-related mechanisms, of which collisions of ions with neutral molecules in the plume and space charge and shielding effects in the ion cloud can be assumed to be most significant. $C$ furthermore accounts for uncertainties in the knowledge of the geometrical parameters used: The overall drift length, $\mathrm{L}$, and the applied voltages. Finally, $\mathrm{C}$ also accounts for two (minor), above mentioned instrumentation-related effects on the overall flight time which are not explicitly accounted for by the terms in eq 1, the deceleration/ 


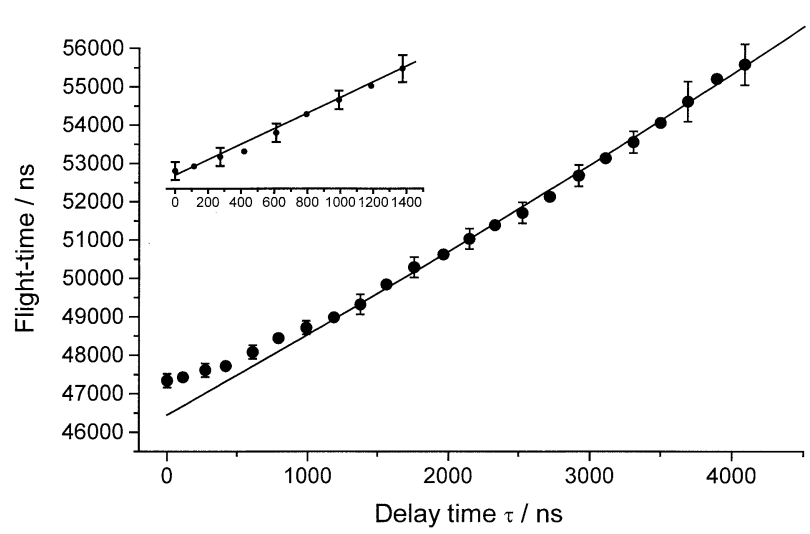

Figure 2. Typical flight-time curve $\mathrm{T}(\tau)$ as used for the determination of the initial ion velocities, in this case for desorption of angiotensin II ions from a glycerol matrix. Flight-times were recorded as a function of the delay time between laser and DE HV pulse. The Er:YAG laser was employed for desorption ionization; the applied DE voltage was $5 \mathrm{kV}$. The solid line is a best-fit of eq 1 to the experimental data in the delay time range between $1200 \mathrm{~ns}$ and the applied maximum delay time of $4200 \mathrm{~ns}$ with $\mathrm{v}_{0}=930$ $\mathrm{ms}^{-1}$ and $\mathrm{C}=1.013$. The inset shows the enlarged small delay time range. A fit to these data in between 200 and 1200 ns would result in a significantly lower $\mathrm{v}_{0}$ of $420 \mathrm{~ms}^{-1}$ (dashed line). The delay time of zero denotes continuous ion extraction.

acceleration in the Einzel lens and the post-acceleration onto the detector. [It should be noted that the traverse time through both ion optical elements also exhibits a slight dependence on the kinetic energy of the incoming ions and hence delay time. This effect was estimated by SIMION simulations and found to be negligible compared to the change of overall flight-times with $\tau$. The additional time introduced by the flight time of secondary ions in the post-acceleration detector, on the other hand, is essentially a constant for a given post-acceleration voltage. For an average secondary ion of mass 50 $\mathrm{Da}$ and a post-acceleration potential of $-15 \mathrm{kV}$ this time can be calculated to about $150 \mathrm{~ns}$ which is negligible compared to the overall flight time of a few ten to a few hundred $\mu \mathrm{s}$ and was therefore not included in eq 1.] Actually, the introduction of this scaling factor has no impact on the determined value of $\mathrm{v}_{0}$, it merely shifts the calculated curve to coincide with the measured one to yield an optimal statistical fit. Typically, $\mathrm{C}$ deviated from a value of 1 by no more than $2 \%$. More importantly, the values of $\mathrm{v}_{0}$, reflecting the slope of the $\mathrm{T}$ versus $\tau$ curve, varied by less than the statistical variation of the values of $1-3 \%$, described above.

The parameters in eq $1 \mathrm{~b}$ to $1 \mathrm{~d}$ affect the course of $\mathrm{T}(\tau)$ in different ways. $\mathrm{L}$ and $\mathrm{U}_{\text {targ }}$ affect essentially the total flight time of the ions and the intersection of the time-of-flight curve with the ordinate. The slope of $\mathrm{T}(\tau)$ is essentially determined by $\mathrm{v}_{0}$ and the field strength $\mathrm{E}$ in the first extraction region.

A typical flight-time plot as used for the determination of $\mathrm{v}_{0}$ is displayed in Figure 2, for the desorption of angiotensin II ions from a glycerol matrix. The bending of the measured flight times towards larger than predicted times for small delay times $\tau$ up to about $1200 \mathrm{~ns}$ was consistently found for liquid and, somewhat less pronounced, for solid-state matrices and can be attributed to the delay time dependent energy deficit ions acquire upon acceleration after the extraction field is switched on (by collisions of partly accelerated ions with slower neutral plume components). This is not accounted for in the flight time eq $1 \mathrm{~b}-1 \mathrm{~d}$. This deficit is particularly large for short delay times of ion extraction and hence, still dense plumes at the instant of ion acceleration. For the determination of $\mathrm{v}_{0}$ only results for long delay times exceeding $1500 \mathrm{~ns}$ were, therefore, used. A best fit to eq 1 is in this case found for a value of $C=1.013$ and $\mathrm{v}_{0}=930 \mathrm{~ms}^{-1}$ (solid line). For comparison a fit to the data in a delay time range between 200 and $1200 \mathrm{~ns}$ is also drawn (dashed line). A best fit in this range of delay times results in a considerably lower $\mathrm{v}_{0}$ of $420 \mathrm{~ms}^{-1}$.

\section{Field-Free Drift Method (FFDM)}

The second method used for determination of mean initial velocities $\mathrm{v}_{0}$ relies on the change in flight time $\mathrm{T}$ upon variation of the field-free distance $S_{1}$ between target and first extraction electrode. Three values of 4 , 6 , and $8 \mathrm{~mm}$ were realized in the experiments by retracting the target relative to $E_{1}$. Ions drift field-free in $S_{1}$ and are accelerated by the static electric field in $\mathrm{S}_{2}$. The initial velocity $\mathrm{v}_{0}$ follows from a the simple relation of $\mathrm{v}_{0}=\Delta \mathrm{S}_{1} / \Delta \mathrm{T}$. With this method, a zerofield in $S_{1}$ is a crucial prerequisite, in particular for small ions for which, for example, fringing fields in a nominally field-free region would influence the flight times substantially. To improve the field conditions, an additional mesh, $\mathrm{N}_{1}$, with $\sim 78 \%$ optical transmission (200 lpi, MN-32, Buckbee-Mears St. Paul, St. Paul, MN) was installed $1 \mathrm{~mm}$ in front of $E_{1}$ towards the target and held at target potential. The remaining field from field penetration through $\mathrm{E}_{1}$ and $\mathrm{N}_{1}$ was compensated by applying a small reverse voltage of $-16 \mathrm{~V}$ (for a total target potential of $12.5 \mathrm{kV}$ ) between $\mathrm{N}_{1}$ and $\mathrm{E}_{1}$. This value was determined by SIMION calculations and verified experimentally for $\mathrm{Na}^{+}$ions as described above. The still remaining residual field strength was estimated from the SIMION calculations to be $\leq 0.075 \mathrm{~V} / \mathrm{mm}$ for $S_{1}=4 \mathrm{~mm}$ and $\leq 0.032 \mathrm{~V} / \mathrm{mm}$ for $\mathrm{S}_{1}=8 \mathrm{~mm}$.

At least twenty single shot mass spectra were summed for each flight-time value as described above. Flight times were determined from the centroid of the ion peak. Because of the additional mesh electrode $\mathrm{N}_{1}$ adjustment of zero-field conditions was comparatively uncritical and the respective error in the determination of $\mathrm{v}_{0}$ due to residual fields in $\mathrm{S}_{1}$ were therefore negligible. The target position could be changed with an accuracy of $\pm 5 \mu \mathrm{m}$ and the resulting error in $\Delta \mathrm{S}$ can thus also be neglected. The main possible systematic error in the FFD method results, therefore, primarily from the dependence of the total ion flight time on the angular acceptance of the mass 
Table 2. (Mean) initial velocities $\mathrm{v}_{0}$ (in $\mathrm{ms}^{-1}$ ) of IR and UV MALDI ions, determined with the delayed extraction (DEM) and the field-free drift method (FFDM) for desorption from different matrices ${ }^{\mathrm{a}}$

\begin{tabular}{|c|c|c|c|c|c|c|c|c|c|c|c|c|c|c|c|c|}
\hline \multirow[b]{3}{*}{ Method: } & \multicolumn{16}{|c|}{ Matrix } \\
\hline & \multicolumn{2}{|c|}{$\begin{array}{l}\text { Glycerol } \\
\text { (92 Da) }\end{array}$} & \multirow{2}{*}{$\begin{array}{c}\begin{array}{c}\text { Di-glycerol } \\
(166 \mathrm{Da})\end{array} \\
\mathrm{DE}\end{array}$} & \multicolumn{2}{|c|}{$\begin{array}{c}\text { Triethanol } \\
\text {-amine } \\
\text { (149 Da) }\end{array}$} & \multicolumn{2}{|c|}{$\begin{array}{c}\text { Lactic acid } \\
\text { (90 Da) }\end{array}$} & \multicolumn{2}{|c|}{$\begin{array}{l}\text { Thiourea } \\
\text { (72 Da) }\end{array}$} & \multicolumn{2}{|c|}{$\begin{array}{l}\text { Succinic } \\
\text { acid } \\
(116 \mathrm{Da})\end{array}$} & \multicolumn{2}{|c|}{$\begin{array}{c}\text { TRIS } \\
(121 \mathrm{Da})\end{array}$} & \multicolumn{3}{|c|}{ DHBs (154 Da) } \\
\hline & DE & FFD & & $\mathrm{DE}$ & FFD & DE & FFD & DE & FFD & $\mathrm{DE}$ & FFD & $\mathrm{DE}$ & FFD & DE FFD & $\mathrm{DE}$ & FFD \\
\hline Matrix ions ${ }^{b}$ & $\begin{array}{r}982 \\
\pm 18\end{array}$ & $\begin{array}{r}1570 \\
\pm 141\end{array}$ & - & $\begin{array}{r}932 \\
\pm 14\end{array}$ & $\begin{array}{r}1282 \\
\pm 115\end{array}$ & $\begin{array}{l}1006 \\
\pm 21\end{array}$ & $\begin{array}{l}888 \\
\pm 75\end{array}$ & $\begin{array}{l}1054 \\
\pm 25\end{array}$ & $\begin{array}{r}1022 \\
\pm 153\end{array}$ & $\begin{array}{r}786 \\
\pm 18\end{array}$ & $\begin{array}{r}1094 \\
\pm 164\end{array}$ & - & - & $\begin{array}{l}511 \quad 741 \\
\pm 15 \pm 111\end{array}$ & $\begin{array}{l}1070 \\
\pm 51\end{array}$ & $\begin{array}{r}911 \\
+136\end{array}$ \\
\hline $\begin{array}{l}\text { Angiotensin I } \\
\text { (1046 Da) }\end{array}$ & $\begin{array}{l}911 \\
\pm 7\end{array}$ & $\begin{array}{r}1389 \\
\pm 141\end{array}$ & - & $\begin{array}{r}875 \\
\pm 11\end{array}$ & $\begin{array}{r}1413 \\
\pm 127\end{array}$ & $\begin{array}{l}888 \\
\pm 14\end{array}$ & $\begin{array}{r}1340 \\
\pm 120\end{array}$ & $\begin{array}{l}1072 \\
\pm 31\end{array}$ & $\begin{array}{r}1129 \\
\pm 169\end{array}$ & $\begin{array}{r}743 \\
\pm 12\end{array}$ & $\begin{array}{c}\mathbf{8 2 1} \\
\pm 112\end{array}$ & $\begin{array}{r}822 \\
\pm 19\end{array}$ & $\begin{array}{c}987 \\
\pm 140\end{array}$ & $\begin{array}{l}704 \quad 915 \\
\pm 22 \pm 137\end{array}$ & $\begin{array}{l}740 \\
\pm 28\end{array}$ & $\begin{array}{r}886 \\
+132\end{array}$ \\
\hline $\begin{array}{l}\text { Cytochrome } C \\
(12,359 \mathrm{Da})\end{array}$ & $\begin{array}{r}882 \\
\pm 15\end{array}$ & $\begin{array}{r}1203 \\
\pm 108\end{array}$ & - & $\begin{array}{r}970 \\
\pm 15\end{array}$ & $\begin{array}{r}1142 \\
\pm 102\end{array}$ & - & - & $\begin{array}{l}939 \\
\pm 20\end{array}$ & $\begin{array}{r}1313 \\
\pm 196\end{array}$ & $\begin{array}{l}735 \\
\pm 17\end{array}$ & $\begin{array}{c}909 \\
\pm 136\end{array}$ & $\begin{array}{l}867 \\
\pm 28\end{array}$ & $\begin{array}{c}904 \\
\pm 135\end{array}$ & $\begin{array}{r}689 \quad 887 \\
\pm 25 \pm 133\end{array}$ & $\begin{array}{l}689 \\
\pm 18\end{array}$ & $\begin{array}{r}783 \\
\pm 117\end{array}$ \\
\hline $\begin{array}{l}\text { Lysozyme } \\
\text { (14,304 Da) }\end{array}$ & $\begin{array}{l}944 \\
\pm 11\end{array}$ & $\begin{array}{r}1186 \\
\pm 107\end{array}$ & $\begin{array}{l}897 \\
\pm 21\end{array}$ & $\begin{array}{l}992 \\
\pm 20\end{array}$ & $\begin{array}{r}1157 \\
\pm 104\end{array}$ & $\begin{array}{l}962 \\
\pm 25\end{array}$ & $\begin{array}{r}1155 \\
\pm 103\end{array}$ & - & - & $\begin{array}{r}672 \\
\pm 22\end{array}$ & $\begin{array}{r}\mathbf{8 4 6} \\
\pm 106\end{array}$ & - & - & - & - & - \\
\hline $\begin{array}{l}\mathrm{BSA}^{\mathrm{c}} \\
(66,400 \mathrm{Da})\end{array}$ & $\begin{array}{l}924 \\
\pm 20\end{array}$ & $\begin{array}{r}1211 \\
\pm 109\end{array}$ & $\begin{array}{l}922 \\
\pm 13\end{array}$ & $\begin{array}{l}932 \\
\pm 13\end{array}$ & $\begin{array}{r}1320 \\
\pm 118\end{array}$ & $\begin{array}{l}910 \\
\pm 18\end{array}$ & $\begin{array}{l}1100 \\
\pm 99\end{array}$ & $\begin{array}{l}922 \\
\pm 24\end{array}$ & $\begin{array}{r}1096 \\
\pm 164\end{array}$ & $\begin{array}{l}692 \\
\pm 21\end{array}$ & $\begin{array}{c}752 \\
\pm 112\end{array}$ & $\begin{array}{r}790 \\
\pm 28\end{array}$ & $\begin{array}{r}1040 \\
\pm 155\end{array}$ & $\begin{array}{ll}\mathbf{6 6 2} & \mathbf{5 4 1} \\
\pm 45 & \pm 81\end{array}$ & $\begin{array}{l}576 \\
\pm 30\end{array}$ & - \\
\hline $\begin{array}{l}\operatorname{lgG}^{d} \\
(150,000 \mathrm{Da})\end{array}$ & $\begin{array}{r}849 \\
\pm 14\end{array}$ & - & - & - & - & - & - & - & - & $\begin{array}{r}637 \\
\pm 32\end{array}$ & - & - & - & - & $\begin{array}{l}441 \\
\pm 24\end{array}$ & - \\
\hline $\begin{array}{l}\text { IgG-dimer } \\
(300,000 \mathrm{Da})\end{array}$ & $\begin{array}{r}852 \\
\pm 25\end{array}$ & - & - & - & - & - & - & - & - & $\begin{array}{l}598 \\
\pm 52\end{array}$ & - & - & - & - & - & - \\
\hline$\lambda_{\text {Laser }}$ & & & & & & & 2.94 & & & & & & & & 337 & $\mathrm{~nm}$ \\
\hline
\end{tabular}

aThe Er:YAG laser $(\lambda=2.94 \mu \mathrm{m})$ was used for IR MALDI and the $\mathrm{N}_{2}$ laser $(\lambda=337 \mathrm{~nm})$ for UV MALDI. The accuracy of the DE method is ca. $10 \%$ for all analyte ions; for FFDM, the maximum possible systematic error is $\sim 20 \%$ (see text for details). Listed are the standard deviation from the mean values.

IInitial matrix ion velocities could only be determined with comparatively large uncertainty and should be treated with care. In case of DHBs the $(\mathrm{M}-\mathrm{OH})^{+}$ion signal at $\mathrm{m} / \mathrm{z} 137$ was used for data evaluation.

${ }^{\mathrm{c} B o v i n e ~ s e r u m ~ a l b u m i n . ~}$

IImmunoglobuline from mouse.

spectrometer, which depends critically on the laser spot localization relative to the TOF axis and, in particular, the settings of the ion lens. The maximum systematic error for the determination of $\mathrm{v}_{0}$ was estimated to $\delta_{\mathrm{v} 0, \max }= \pm 20 \%$, based on experimental tests of the worst case scenario (positioning the laser spot off-axis and varying the ion lens focusing conditions.)

Standard deviations, $\sigma_{\mathrm{v} 0}$, were determined for glycerol and succinic acid as representative for liquid and solid-state matrices to $\sim \pm 9 \%$ for glycerol and $\sim \pm 15 \%$ for succinic acid. Only the standard deviations are listed in the tables. For both DEM and FFDM, the tabulated initial velocity values (Tables $2-5$ ) are the average of up to ten individual measurements.

\section{Results}

Influence of the Matrix and the Mass of Analyte Ions

Table 2 summarizes the initial velocities for analyte and matrix ions for various solid-state and liquid matrices, determined by DEM and FFDM.

For DEM, fluence was adjusted to about 1.2-1.4 times the individual matrix-dependent ion threshold fluence, $\mathrm{H}_{0}$. The determination of absolute fluence values was beyond the scope of this study, these values have been determined previously for comparable exposure conditions in the same instrument for some of the matrices [42, 43].

Due to the additional $\mathrm{N}_{1}$ mesh and the reduced transmission conditions, the applied fluence was generally somewhat higher and less well defined for FFDM. For IR MALDI the FFD method was found useful up to a mass of about $70 \mathrm{kDa}$ (BSA). The very long flight times for ions of even higher masses (e.g., mouse IgG, $150 \mathrm{kDa}$ ), accompanied by a very limited quality of the mass spectra, led to an unacceptably large uncertainty in the time-of-flight. These values were therefore excluded from the table. For UV MALDI the usable mass range for FFDM was limited to about the mass of trypsin of $\sim 24 \mathrm{kDa}$ (data not shown).

The mean initial velocities acquired with the $\mathrm{DE}$ method fall into the range of ca. $500-1000 \mathrm{~ms}^{-1}$. The corresponding FFDM values lie in between ca. 800$1500 \mathrm{~ms}^{-1}$ (with the exception of BSA desorbed from a dried-droplet DHBs preparation). Particularly large differences between the DEM and the FFDM values were found for the liquid matrices TEA and glycerol for which the two measurement methods differed by up to $350 \mathrm{~m}^{-1}$ under otherwise identical conditions. Within the margins of the (rather conservatively) estimated maximum possible systematic error of about $10 \%$ for the DE and $20 \%$ for the FFD method, respectively, the 
Table 3. Mean initial velocities $\mathrm{v}_{0}$ (in $\mathrm{ms}^{-1}$ ) of gramicidin $S(1141 \mathrm{Da})$ and cytochrome $C$ (12359 Da) ions for desorption from samples with different molar analyte-to-matrix ratios (A/M). Matrix: succinic acid. ${ }^{a}$

\begin{tabular}{|c|c|c|c|c|c|c|c|c|}
\hline \multirow{2}{*}{$\begin{array}{l}\text { Method: } \\
\text { Analyte }\end{array}$} & \multicolumn{6}{|c|}{$\mathrm{DE}$} & \multicolumn{2}{|l|}{ FFD } \\
\hline & $\mathrm{A} / \mathrm{M} \sim 10^{-6}$ & $\mathrm{~A} / \mathrm{M} \sim 10^{-5}$ & $\mathrm{~A} / \mathrm{M} \sim 10^{-4}$ & $\mathrm{~A} / \mathrm{M} \sim 10^{-3}$ & $\mathrm{~A} / \mathrm{M} \sim 10^{-2}$ & $\mathrm{LDI}^{\mathrm{b}}$ & $\mathrm{A} / \mathrm{M} \sim 10^{-3}$ & $\overline{\text { LDI }}$ \\
\hline \multirow[t]{2}{*}{ Gramicidin $S$} & - & 725 & 705 & 753 & 577 & 476 & 794 & 443 \\
\hline & & \pm 20 & \pm 36 & \pm 27 & \pm 24 & \pm 21 & \pm 119 & \pm 85 \\
\hline \multirow[t]{2}{*}{ Cytochrome $C$} & 698 & 728 & 741 & 603 & 515 & 531 & & \\
\hline & \pm 20 & \pm 33 & \pm 24 & \pm 29 & \pm 47 & \pm 57 & & \\
\hline
\end{tabular}

aThe Er:YAG laser $(\lambda=2.94 \mu \mathrm{m})$ was utilized in all cases. In the case of the frozen hydrated samples (LDI) a cooled target stage was used. In case of gramicidin $S$ ion velocities were determined from the quasi-molecular cation signals. The accuracy of the DE method is ca. $10 \%$ for all analyte ions; for FFDM, the maximum possible systematic error is $\sim 20 \%$ (see text for details). Listed are the standard deviation from the mean values.

bLDI: Direct laser desorption/ionization from a frozen hydrated preparation without (organic) matrix.

velocity values obtained by the two methods barely overlap. Although on statistical grounds the observed differences are hence not significant, a tendency towards the determination of higher initial velocity values with the FFD method is well perceivable.

Although both measurement methods have a high uncertainty for small matrix ions, a general correlation between the mean initial velocities of analyte ions with those of the corresponding matrix ions is found in the data. Finally, considering the different excitation and, therefore, probably ablation mechanisms in the two wavelength regions, the good agreement between analyte velocities in IR and UV MALDI for desorption from a DHBs matrix is particularly noteworthy. In IRMALDI, the size of the analyte molecules appears to play a rather minor role. For UV-MALDI, a tendency towards a decreasing $\mathrm{v}_{0}$ is found with increasing molecular weight for both methods.

\section{Influence of the Analyte-to-Matrix Ratio}

The potential influence of the molar analyte-to-matrix ratio $(\mathrm{A} / \mathrm{M})$ on the initial velocities was mainly examined with the DE method for a succinic acid matrix and gramicidin $S(1141 \mathrm{Da})$ and cytochrome $C$ (12359 Da) as analytes. These results are summarized in Table 3.

Over an A/M range of three orders of magnitude, comparable initial velocities were measured for both analytes. Clearly discernible is a decrease in velocity for the gramicidin $S$ ion at an $\mathrm{A} / \mathrm{M}$ of about $10^{-2}$; for cytochrome $C$ a similar decrease is found already at an
$\mathrm{A} / \mathrm{M}$ of about $10^{-3}$. For the extreme case of direct laser desorption/ionization (LDI, no matrix added) notably lower initial velocities in the range of $500 \mathrm{~ms}^{-1}$ were measured. Whereas gramicidin $S$ ions can be generated from completely lyophilized samples (data not shown), the preservation of a thin shell of water of hydration is a necessary prerequisite for the analysis of cytochrome $C$ ions from such frozen hydrated preparations [40].

Despite the lack of entrainment into a stream of matrix molecules comparable initial velocities were determined for both analyte ions in the LDI case. For LDI from the frozen-hydrated matrices almost identical values are, moreover, found for DEM and FFDM in contrast to the MALDI preparations.

\section{Influence of the Laser Fluence}

The influence of the laser fluence on the mean initial velocities was investigated with the DE method, only. A wavelength of $2.94 \mu \mathrm{m}$ and an uniform laser beam profile on the target was used. Glycerol, di-glycerol, triethanolamine, and succinic acid were tested in this set of experiments, in combination with lysozyme and bovine serum albumin (BSA) as analytes. The results are shown in Table 4. Fluences were varied in the MALDI relevant energy range from ca. $1.2 \mathrm{H}_{0}$ to at most $2.0 \mathrm{H}_{0}$. No significant fragmentation reactions were observed in this fluence range.

For the liquid matrices the mean initial velocities were found to increase with increasing fluence. This effect is particularly apparent for glycerol, where the

Table 4. Mean initial velocities $\mathrm{v}_{0}$ (in $\left.\mathrm{ms}^{-1}\right)$ of lysozyme $(14.3 \mathrm{kDa})$ and bovine serum albumin (BSA, $\left.66.4 \mathrm{kDa}\right)$ ions and different matrices as a function of the laser fluence $\mathrm{H}$. DE method $^{\mathrm{a}}$

\begin{tabular}{|c|c|c|c|c|c|c|c|c|}
\hline \multirow[b]{2}{*}{ Analyte } & \multicolumn{2}{|c|}{ Glycerol } & \multicolumn{2}{|c|}{ Di-glycerol } & \multicolumn{2}{|c|}{ TEA } & \multicolumn{2}{|c|}{ Succinic acid } \\
\hline & $1.2 \mathrm{H}_{0}$ & ca. $2 \mathrm{H}_{0}$ & $1.3 \mathrm{H}_{0}$ & $1.6 \mathrm{H}_{0}$ & $1.2 \mathrm{H}_{0}$ & $1.8 \mathrm{H}_{0}$ & $1.2 \mathrm{H}_{0}$ & $1.8 \mathrm{H}_{0}$ \\
\hline Lysozyme & $\begin{array}{l}913 \\
\pm 15\end{array}$ & $\begin{array}{l}1104 \\
\pm 21\end{array}$ & $\begin{array}{l}897 \\
\pm 22\end{array}$ & $\begin{array}{l}941 \\
\pm 28\end{array}$ & $\begin{array}{l}928 \\
\pm 11\end{array}$ & $\begin{array}{l}1050 \\
\pm 24\end{array}$ & $\begin{array}{l}723 \\
\pm 37\end{array}$ & $\begin{array}{l}750 \\
\pm 45\end{array}$ \\
\hline BSA & $\begin{array}{l}887 \\
\pm 10\end{array}$ & $\begin{array}{l}1039 \\
\pm 18\end{array}$ & $\begin{array}{l}922 \\
\pm 20\end{array}$ & $\begin{array}{l}939 \\
\pm 25\end{array}$ & $\begin{array}{l}950 \\
\pm 16\end{array}$ & $\begin{array}{l}996 \\
\pm 18\end{array}$ & $\begin{array}{l}722 \\
\pm 33\end{array}$ & $\begin{array}{l}742 \\
\pm 29\end{array}$ \\
\hline
\end{tabular}

aThe Er:YAG laser $(2.94 \mu \mathrm{m})$ was used in all cases. $\mathrm{H}_{0}$ denotes the individual, matrix-dependent threshold fluence for detection of analyte ions. For all samples analytes were prepared in $\mathrm{A} / \mathrm{M}$ ratios of $10^{-5}-10^{-4}$. The accuracy of the DE method is ca. $10 \%$ for all analyte ions (see text for details). Listed are the standard deviation from the mean value. 


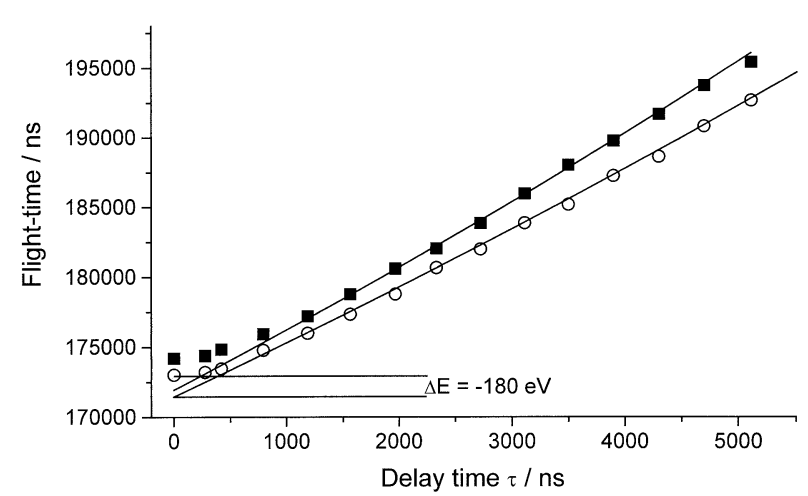

Figure 3. Flight-time curves $\mathrm{T}(\tau)$ of lysozyme ions desorbed from a glycerol matrix as a function of the delay time $\tau$ between laser and DE HV pulse, recorded with laser fluences of (open circle) 1.2 $\mathrm{H}_{0}$ and (filled square) $2 \mathrm{H}_{0}$. The two solid lines correspond to best-fits to eq 1 with a $\mathrm{v}_{0}$ of 920 and $1110 \mathrm{~ms}^{-1}$, respectively. The delay time of zero denotes continuous ion extraction. The indicated $\Delta \mathrm{E}$ denotes estimated energy deficit ions acquire upon collisions during ion extraction or as a result of field-shielding effects. $\Delta \mathrm{E}$ is estimated from the difference between the experimental and theoretical ion flight time at $\tau=0$. The theoretical flight time is calculated from eq 1 as a fit to the experimental flight times in the delay time range from 1500 to 5000 ns. Energy deficits $\Delta \mathrm{E}$ of $-180 \mathrm{eV}$ and $-320 \mathrm{eV}$ were found for $\mathrm{H}=1.2 \mathrm{H}_{0}$. and $\mathrm{H}=$ $2 \mathrm{H}_{0}$, respectively. Only the first is indicated in the figure by an inset. See text for further explanation.

fluence can be raised up to a factor of about two times threshold without causing significant ion fragmentation: For this matrix a change in fluence from 1.2 to $2 \times$ $\mathrm{H}_{0}$ is accompanied by an increase in analyte ion velocity by about $20 \%$. In contrast to the liquid matrices, no notable influence of the fluence on the analyte velocities was observed for desorption from the solid-state matrices. Similar results were obtained with DHBs, and thiourea as solid matrices and gramicidin $S$ as analyte (recorded with a Gaussian laser beam profile; data not shown). Initial ion velocities were also found to be widely independent on IR laser fluence in a recent study by Ermer et al. [29].

Figure 3 displays the time-of-flight curves $\mathrm{T}(\tau)$ of lysozyme ions desorbed from a glycerol matrix at a low and a high laser fluence. Aside from the increase of the initial velocities with fluence, the figure also demonstrates the putative influence of collision-induced energy deficits on the flight time curves. The magnitude of the energy deficit at $\tau=0$ (static ion extraction) can be estimated from a comparison of the experimental flight times at $\tau=0$ to the fit the curve derived for long delay times $\tau$ (for which collisions are assumed to be of minor influence). For lysozyme ions, an energy deficit of about $-180 \mathrm{eV}$ is derived for a fluence of $1.2 \mathrm{H}_{0}$. This deficit increases with fluence to about $-320 \mathrm{eV}$ at $2.0 \mathrm{H}_{0}$.

The energy deficit was found to depend on the mass of the analyte ions. For bovine serum albumin (BSA) ions, for example, values of $-200 \mathrm{eV}$ at $1.2 \mathrm{H}_{0}$ and -450 $\mathrm{eV}$ at $2.0 \mathrm{H}_{0}$ were determined. The described trend was consistently seen for all liquid matrices. Again, solidstate matrices behave distinctly differently: No system-
Table 5. Mean initial velocities $\mathrm{v}_{0}\left(\right.$ in $\mathrm{ms}^{-1}$ ) as a function of laser wavelength, determined with the delayed extraction method (DEM) for analyte ions of different molecular weight. Matrix: Glycerol ${ }^{\mathrm{a}}$

\begin{tabular}{|c|c|c|c|}
\hline \multirow[b]{2}{*}{ Analyte } & \multicolumn{3}{|c|}{ Laser wavelength $\lambda$} \\
\hline & $2.94 \mu \mathrm{m}$ & $2.79 \mu \mathrm{m}$ & $10.59 \mu \mathrm{m}$ \\
\hline$\alpha_{\lambda} / \alpha_{2.94 \mu \mathrm{m}}:^{\mathrm{b}}$ & 1 & $0.125-0.20$ & $0.05-0.10$ \\
\hline $\begin{array}{l}\text { Angiotensin I } \\
(1046 \mathrm{Da})\end{array}$ & $\begin{array}{l}915 \\
\pm 18\end{array}$ & $\begin{array}{l}952 \\
\pm 36\end{array}$ & $\begin{array}{l}912 \\
\pm 26\end{array}$ \\
\hline $\begin{array}{l}\text { Cytochrome } C \\
\text { (12359 Da) }\end{array}$ & $\begin{array}{l}936 \\
\pm 13\end{array}$ & $\begin{array}{l}832 \\
\pm 25\end{array}$ & $\begin{array}{l}936 \\
\pm 22\end{array}$ \\
\hline $\begin{array}{l}\mathrm{BSA}^{\mathrm{c}} \\
(66.4 \mathrm{kDa})\end{array}$ & $\begin{array}{l}859 \\
\pm 19\end{array}$ & $\begin{array}{l}772 \\
\pm 11\end{array}$ & $\begin{array}{l}790 \\
\pm 43\end{array}$ \\
\hline $\begin{array}{l}\operatorname{lgG}^{d} \\
(150 \mathrm{kDa})\end{array}$ & $\begin{array}{l}871 \\
\pm 25\end{array}$ & $\begin{array}{l}797 \\
\pm 16\end{array}$ & $\begin{array}{l}764 \\
\pm 32\end{array}$ \\
\hline
\end{tabular}

aThree different IR lasers were employed: An Er:YAG $(\lambda=2.94 \mu \mathrm{m})$, an Er:YSGG $(\lambda=2.79 \mu \mathrm{m})$, and a $\mathrm{CO}_{2}$ laser $(\lambda=10.59 \mu \mathrm{m})$. The accuracy of the DE method is ca. $10 \%$ for all values (see text for details). Listed are the standard deviation from the mean value.

${ }^{b}$ Ratio of absorption coefficient at the applied laser wavelength and at $2.94 \mu \mathrm{m}$.

"Bovine serum albumin.

Immunoglobuline from mouse.

atic influence of the laser fluence on the energy deficit was found for these matrices. The energy deficit and its distribution function have also been measured by the authors in another set of experiments with high and low pass energy filters (to be published separately). The results found in that work are in agreement with the values reported here.

\section{Influence of the Laser Wavelength}

The possible influence of the laser wavelength on the mean initial velocities was investigated by DEM for the three wavelengths of $2.79 \mu \mathrm{m}$ (Er:YSGG laser), $2.94 \mu \mathrm{m}$ (Er:YAG laser), and $10.59 \mu \mathrm{m}\left(\mathrm{CO}_{2}\right.$ laser). Only glycerol was employed as matrix in this experiment because it gives comparable MALDI results at all three wavelengths. The three laser systems were adjusted to equal laser pulse widths of 80-90 ns. An important parameter in this comparison is the absorption coefficient and the corresponding volume density of absorbed energy at the three wavelengths. The molar decadic extinction (absorption) coefficient of glycerol at $2.94 \mu \mathrm{m}$ was measured recently by the authors in a laser transmission experiment to $100-200 \mathrm{l} \mathrm{mol}^{-1} \mathrm{~cm}^{-1}$ for thin layers of glycerol and typical MALDI fluences [43]. With the absolute value for the absorption coefficient at one wavelength, the values at the other two wavelengths can be deduced from baseline-corrected IR transmission spectra albeit with considerable uncertainty. From the baseline-corrected FTIR spectrum provided in the Sigma-Aldrich database [44] the factors are estimated to: $\alpha_{2.94 \mu \mathrm{m}} \approx(4-8) \times \alpha_{2.79 \mu \mathrm{m}} \approx(10-20) \times \alpha_{10.59 \mu \mathrm{m}}$. Probably as a result of the significantly lower absorption coefficient, $\mathrm{CO}_{2}$ laser irradiation was accompanied by a visually perceivable ablation of significantly larger sam- 
ple volumes [45]. The mean initial velocities obtained for the three wavelengths are displayed in Table 5.

Despite the strongly different absorption coefficients at the three laser wavelength almost no influence on the initial ion velocities is observed. For BSA ions somewhat lower velocities were measured for the Er:YSGG and the $\mathrm{CO}_{2}$ lasers, but no overall general trend is discernible.

\section{Discussion}

The results show that an accurate measurement of initial velocities of MALDI ions remains a challenge and, in agreement with the results in the literature, the outcome to some extent depends on the measurement method. The DE method, utilized in the recent past in several studies, is attractive because it is simple in principle. Furthermore, it can be used with commercial DE time-of-flight instruments. Unfortunately, this method is rather indirect. As discussed above, collisions of (partly) accelerated ions with neutral plume constituents after application of the DE HV extraction pulse must be assumed to lead to a significant modification of the final ion velocities. The extent of this energy deficit will be higher the earlier ion acceleration sets in, i.e., the lower the delay time $\tau$. At these low delay times the flight time $[\mathrm{T}(\tau)]$ curves, used for evaluation of the velocities, exhibit considerably lower slope and, hence, lower values for the initial velocities are derived.

Because of the much larger volume of ablated material, the extent of this collision-induced artifact is particularly visible for IR MALDI. However, an influence on the flight-time curves at small delay times was also recognizable in some of the UV MALDI curves (data not shown). Besides the collision-effect, an effective shielding of the acceleration field by the dense plume can also cause a flight-time $=\tau$ dependence.

The discussed effects can probably also explain the obvious differences between the initial velocities as determined in our present study and some of those previously reported for UV MALDI by the DE method. For insulin desorbed from DHB values of $\sim 500$ and 550 $\mathrm{ms}^{-1}$ were, for example, reported in [5] and [17], respectively, compared to about $700 \mathrm{~ms}^{-1}$ obtained in our work. Only delay times up to 600 and $1200 \mathrm{~ns}$, respectively, were applied in the previous studies and a comparatively low $\mathrm{S}_{1}$ employed.

In contrast to the DEM values, our results for the initial velocities compare well with the previous FFDM data [18-20, 23, 25]. In the field-free drift methods ions pass through a relatively long field-free region, in our study of 4,6 , or $8 \mathrm{~mm}$, before they are accelerated in the second stage, $\mathrm{S}_{2}$. Because ion acceleration affects a significantly diluted MALDI plume at already the smallest distance of $S_{1}$, the effect of the energy deficit will be much smaller. As has been pointed out before $[17,23]$, in the FFD method the ablation plume expands radially considerably in the field free region, before ions are accelerated towards the TOF axis. Depending on the geometry of the ion source, refocusing of the beam by the ion lens, if present, and the detector size, only the most axially-pointed fraction of the ions will be recorded. This center portion will, on average, contain ions with higher (axial) velocities [19, 23, 35]. For the experimental conditions used in this study such a discrimination has indeed been substantiated by a SIMION simulation. The field-free method will, therefore, tend to yield values for the mean initial axial velocities which are higher than those averaged over all directions. For UV MALDI particularly high velocities of MALDI ions have indeed been determined when the field-free drift method was applied [18-20, 23, 29].

As a result of these considerations it appears reasonable to assume that the true initial axial ion velocity component $\mathrm{v}_{0}$ lies between the limits set by the DEM and the FFDM values.

For both methods the mean initial velocities of analyte ions in IR MALDI consistently approach those of the matrix ions, in agreement with the results for UV MALDI [5, 17-20, 24]. Within the limits of experimental accuracy, particularly for the low mass matrix ions, it can hence be concluded that for MALDI typical A/M ratios and fluences, the dynamic parameters in the expanding plume and, hence, also the velocities of the imbedded analyte ions, are essentially determined by the physico-chemical properties of the matrix compound.

Considerable effort has been made in the past to understand the high initial velocities of laser desorbed molecules and ions. Simple thermal surface desorption models, for example, would predict significantly lower initial velocities than experimentally observed under reasonable assumptions for the achieved peak temperature. The conditions in MALDI, particularly IR MALDI, however, hardly match surface desorption conditions. It rather involves the excitation and ablation of a macroscopic volume of between 1 to $100 \mu \mathrm{m}$ in thickness, a possibly considerable build-up of pressure in the sample, as well as a high number of collisions between matrix and analyte molecules/ions. The surprisingly similar initial ion velocities, essentially independent of the laser wavelength (Tables 2 and 5), i.e., primary excitation mechanism, laser penetration depth, and amount of ablated material, as well as molecular analyte mass (Table 2) therefore obviously originate from the physico-chemical material properties and phase transition as well as plume expansion process rather than from the exact pathway of laser excitation.

Thermal velocities of subliming/evaporating molecules will be superimposed on the strongly forwardpeaked movement. Consequently, only the radial plume velocities would reflect the actual plume temperature, as has been discussed in the literature before.

Recent MD simulations by Zhigilei and Garrison can also help to solve the open questions [35]. These simulations revealed comparably high center of mass velocities for both simulated UV and approximated IR MALDI conditions. 


\section{Acknowledgments}

This work was supported by the Deutsche Forschungsgemeinschaft (DFG; under grant no. HI 285/8-2) and the Bundesministerium für Bildung und Forschung (BMBF, grant no. 0311419). It was carried out in partial fulfillment of the requirements for the degree of Dr. rer. nat. of S.B. at the University of Münster.

\section{References}

1. Colby, S. M.; King, T. B.; Reilly, J. P. Improving the Resolution of Matrix-Assisted Laser Desorption/Ionization Time-ofFlight Mass Spectrometry by Exploiting the Correlation between Ion Position and Velocity. Rapid Commun. Mass Spectrom. 1994, 8, 865-868.

2. Brown, R. S.; Lennon, J. J. Mass Resolution Improvement by Incorporation of Pulsed Ion Extraction in a Matrix-Assisted Laser- Desorption Ionization Linear Time-of-Flight Mass Spectrometer. Anal. Chem. 1995, 67, 1998-2003.

3. Takach, E. J.; Hines, W. M.; Patterson, D. H.; Juhasz, P.; Falick, A. M.; Vestal, M. L.; Martin, S. A. Accurate Mass Measurements Using MALDI-TOF with Delayed Extraction. J. Prot. Chem. 1997, 16, 363-369.

4. Berkenkamp, S.; Menzel, C.; Hillenkamp, F. Performance of Infrared Matrix-Assisted Laser Desorption/Ionization Mass Spectrometry with Lasers Emitting in the $3 \mu \mathrm{m}$ wavelength range. Rapid Commun. Mass Spectrom. 1997, 11, 1399-1406.

5. Juhasz, P.; Vestal, M. L.; Martin, S. A. On the Initial Velocity of Ions Generated by Matrix-Assisted Laser Desorption Ionization and its Effect on the Calibration of Delayed Extraction Time-of-Flight Mass Spectra. J. Am. Soc. Mass Spectrom. 1997, 8 , 209-217.

6. Vestal, M. L.; Juhasz, P. Resolution and Mass Accuracy in Matrix-Assisted Laser Desorption Ionization Time-of-Flight. J. Am. Soc. Mass Spectrom. 1998, 9, 892-911.

7. van der Peyl, G. J. Q.; van der Zande, W. J.; Kistemaker, P. G. Kinetic Energy Distributions of Ions Produced in Organic Laser Desorption. Int. J. Mass Spectrom. Ion Processes 1984, 62, 51-71.

8. Engelke, F.; Hahn, J. H.; Henke, W.; Zare, R. N. Determination of Phenylthiohydantoin-Amino Acids by Two-Step Laser Desorption/Multiphoton Ionization. Anal. Chem. 1987, 59, 909912.

9. Voumard, P.; Zenobi, R.; Zhan, Q. Laser-Induced ThermalDesorption of Aniline from a Quartz Surface. Surf. Sci. 1994, 307, 360-366.

10. Elam, J. W.; Levy, D. H. Laser Ablation of Trp-Gly. J. Phys. Chem. B 1998, 102, 8113-8120.

11. Tabet, J.-C.; Cotter, R. J. Time-Resolved Laser Desorption Mass Spectrometry. II. Measurement of the Energy Spread of Laser Desorbed Ions. Int. J. Mass Spectrom. Ion Processes 1983, 54, 151-158.

12. Buck, M.; Hess, P. Pulsed Laser-Induced Desorption from Molecular Systems Studies by Time-of-Flight Analysis: Measurement and Interpretation. J. Electron Spectrosc. Relat. Phenom. 1987, 45, 237-247.

13. Danielzik, B.; Fabricius, N.; Röwekamp, M.; van der Linde, D. Velocity Distribution of Molecular Fragments from Polymethylmethacrylate Irradiated with UV Laser Pulses. Appl. Phys. Lett. 1986, 48, 212-214.

14. Yang, M.; Reilly, J. P. Kinetic Energy Distributions of Aniline Molecules and Cations Following their UV-Laser-Induced Desorption from a Metal Surface. J. Phys. Chem. 1990, 94, 6299-6305.

15. Spengler, B.; Cotter, R. J. Ultraviolet Laser Desorption/Ionization Mass Spectrometry of Proteins above 100,000 Daltons by
Pulsed Ion Extraction Time-of-Flight Analysis. Anal. Chem. 1990, 62, 793-796.

16. Schurenberg, M.; Schulz, T.; Dreisewerd, K.; Hillenkamp, F. Matrix-Assisted Laser Desorption/Ionization in Transmission Geometry: Instrumental Implementation and Mechanistic Implications. Rapid Commun. Mass Spectrom. 1996, 10, 1873-1880.

17. Gluckmann, M.; Karas, M. Special Feature: Perspective-The Initial Ion Velocity and Its Dependence on Matrix, Analyte and Preparation Method in Ultraviolet Matrix-Assisted Laser Desorption Ionization. J. Mass Spectrom. 1999, 34, 467-477.

18. Beavis, R. C.; Chait, B. T. Velocity Distributions of Intact High Mass Polypeptide Molecule Ions Produced by Matrix-Assisted Laser Desorption. Chem. Phys. Lett. 1991, 181, 479-484.

19. Zang, W.; Chait, B. T. Radial Velocity Distributions of Molecular Ions Produced by Matrix-Assisted Laser Desorption/ Ionization. Int. J. Mass Spectrom. Ion Processes 1997, 160, 259267.

20. Pan, Y.; Cotter, R. J. Measurement of Initial Translational Energies of Peptide Ions in Laser Desorption/Ionization Mass Spectrometry. Org. Mass Spectrom. 1992, 27, 3-8.

21. Huth-Fehre, T.; Becker, C. H. Energetics of Gramicidin S after UV Laser Desorption from a Ferulic Acid Matrix. Rapid Commun. Mass Spectrom. 1991, 5, 378-382.

22. Zhou, J.; Ens, W.; Standing, K. G.; Verentchikov, A. Kinetic Energy Measurements of Molecular Ions Ejected into an Electric Field by Matrix-Assisted Laser Desorption. Rapid Commun. Mass Spectrom. 1992, 6, 671-678.

23. Spengler, B.; Bökelmann, V. Angular and Time Resolved Intensity Distributions of Laser-Desorbed Matrix Ions. Nucl. Instrum. Meth. Phys. Res. B 1993, 82, 379-385.

24. Bökelmann, V.; Spengler, B.; Kaufmann, R. Dynamic Parameters of Ion Ejection and Ion Formation in Matrix-Assisted Laser Desorption/Ionization. Eur. Mass Spectrom. 1995, 1, 81-93.

25. Zhang, W. Z.; Chait, B. T. Radial Velocity Distributions of Molecular Ions Produced by Matrix-Assisted Laser Desorption/Ionization. Int. J. Mass Spectrom. Ion Processes 1997, 160, 259-267.

26. Kinsel, G. R.; Edmondson, R. D.; Russell, D. H. Profile and Flight Time Analysis of Bovine Insulin Clusters as a Probe of Matrix-Assisted Laser Desorption/Ionization Ion Formation Dynamics. J. Mass Spectrom. 1997, 32, 714-722.

27. Puretzky, A. A.; Geohegan, D. B.; Hurst, G. B. Imaging of Vapor Plumes Produced by Matrix Assisted Laser Desorption: A Plume Sharpening Effect. Phys. Rev. Lett. 1999, 83, 444-447.

28. Kinsel, G. R.; Gimon-Kinsel, M. E.; Gillig, K. J.; Russell, D. H. Investigation of the Dynamics of Matrix-Assisted Laser Desorption Ionization Ion Formation Using an Electrostatic Analyzer/Time-of-Flight Mass Spectrometer. J. Mass Spectrom. 1999, 34, 684-690.

29. Ermer, E. R.; Baltz-Knorr, M.; Haglund, R. F. Intensity Dependence of Cation Kinetic Energies from 2,5-Dihydroxybenzoic Acid near the Infrared Matrix-Assisted Laser Desorption/ Ionization Threshold. J. Mass Spectrom. 2001, 36, 538-545.

30. Vertes, A.; Iriny, G.; Gijbels, R. Hydrodynamic Model of Matrix-Assisted Laser Desorption Mass Spectrometry. Anal. Chem. 1993, 65, 2389-2393.

31. Franzen, J. Improved Resolution for MALDI-TOF Mass Spectrometers: A Mathematical Study. Int. J. Mass Spectrom. Ion Processes 1997, 164, 19-34.

32. Johnson, R. E.; LeBeyec, Y. Angular Distribution of the Ejecta in Matrix-Assisted Laser Desorption/Ionization: Model Dependence. Int. J. Mass Spectrom. 1998, 177, 111-118.

33. Zhigilei, L. V.; Garrison, B. J. Velocity Distributions of Molecules Ejected in Laser Ablation. Appl. Phys. Lett. 1997, 71, 551-553. 
34. Zhigilei, L. V.; Garrison, B. J. Velocity Distributions of Analyte Molecules in Matrix-Assisted Laser Desorption from Computer Simulations. Rapid Commun. Mass Spectrom. 1998, 12, 1273-1277.

35. Zhigilei, L. V.; Garrison, B. J. Microscopic Mechanisms of Laser Ablation of Organic Solids in the Thermal and Ttress Confinement Irradiation Regimes. J. Appl. Phys. 2000, 88, 1281-1298.

36. Bencsura, A.; Navale, V.; Sadeghi, M.; Vertes, A. Matrix-Guest Energy Transfer in Matrix-Assisted Laser Desorption. Rapid Commun. Mass Spectrom. 1997, 11, 679-682.

37. Wu, X. W.; Sadeghi, M.; Vertes, A. Molecular Dynamics of Matrix-Assisted Laser Desorption of Leucine Enkephalin Guest Molecules from Nicotinic Acid Host Crystal. J. Phys. Chem. B 1998, 102, 4770-4778.

38. Noorbatcha, I.; Lucchese, R. R.; Zeiri, Y. Effects of Gas-Phase Collissions on Particles Rapidly Desorbed from Surfaces. Phys. Rev. B 1987, 36, 4978-4981.

39. Kelly, R.; Dreyfus, R. W. Reconsidering the Mechanisms of Laser Sputtering with Knudsen-Layer Formation Taken Into Account. Nucl. Instrum. Meth. Phys. Res. B 1988, 32, 241-348.

40. Berkenkamp, S.; Karas, M.; Hillenkamp, F. Ice as a Matrix for IR-Matrix-Assisted Laser Desorption/Ionization: Mass Spec- tra from a Protein Single Crystal. Proc. Natl. Acad. Sci. U.S.A. 1996, 93, 7003-7007.

41. Ring, S.; Rudich, Y. A Comparative Study of a Liquid and a Solid Matrix in Matrix-Assisted Laser Desorption/Ionization Time-of-Flight Mass Spectrometry and Collision Cross Section Measurements. Rapid Commun. Mass Spectrom. 2000, 14, 515519.

42. Feldhaus, D.; Menzel, C.; Berkenkamp, S.; Hillenkamp, F.; Dreisewerd, K. Influence of the Laser Fluence in Infrared Matrix-Assisted Laser Desorption/Ionization with a $2.94 \mu \mathrm{m}$ Er: YAG Laser and a Flat-Top Beam Profile. J. Mass Spectrom. 2000, 35, 1320-1328.

43. Menzel, C.; Dreisewerd, K.; Berkenkamp, S.; Hillenkamp, F. Mechanisms of Energy Deposition in Infrared Matrix-Assisted Laser Desorption/Ionization Mass Spectrometry. Int. J. Mass Spectrom. 2001, 207, 73-96.

44. Keller, R. J. The Sigma Library of FT-IR Spectra, Vols. I and II; Sigma Chemical Company Inc., 1986.

45. Menzel, C.; Berkenkamp, S.; Hillenkamp, F. Infrared MatrixAssisted Laser Desorption/Ionization Mass Spectrometry with a Transversely Excited Atmospheric Pressure Carbon Dioxide Laser at $10.6 \mu \mathrm{m}$ Wavelength with Static and Delayed Ion Extraction. Rapid Commun. Mass Spectrom. 1999, 13, 26-32. 